\title{
Does the Public Prefer Health Gain for Cancer Patients? A Systematic Review of Public Views on Cancer and its Characteristics
}

\author{
Liz Morrell $^{1}\left(\mathbb{D} \cdot\right.$ Sarah Wordsworth $^{2,3} \cdot$ Sian $^{\text {Rees }^{4}} \cdot$ Richard Barker $^{1}$
}

Published online: 29 April 2017

(C) The Author(s) 2017. This article is an open access publication

\begin{abstract}
Background Policies such as the Cancer Drugs Fund in England assumed a societal preference to fund cancer care relative to other conditions, even if that resulted in lower health gain for the population overall.

Objective The aim of this study was to investigate the evidence for such a preference among the UK public.

Methods The MEDLINE, PubMed and Econlit electronic databases were searched for studies relating to preferences for prioritising cancer treatment, as well as studies relating to preferences for the characteristics of cancer (severity of disease, end-of-life). The searches were run in November 2015 and updated in March 2017. Empirical preference studies, studies of public views, and studies in English were included.

Results We identified 24 studies relating to cancer preferences. Two directly addressed health trade-offs in the UK-one showed a preference for health gain in cancer,
\end{abstract}

Electronic supplementary material The online version of this article (doi:10.1007/s40273-017-0511-7) contains supplementary material, which is available to authorized users.

Liz Morrell

liz.morrell@casmi.org.uk

1 Centre for the Advancement of Sustainable Medical Innovation (CASMI), University of Oxford, Room 4403, Level 4, John Radcliffe Hospital, Headley Way, Headington, Oxford OX3 9DU, UK

2 Nuffield Department of Population Health, Health Economics Research Centre, University of Oxford, Oxford, UK

3 Oxford NIHR Biomedical Research Centre, University of Oxford, Oxford, UK

4 Nuffield Department of Primary Care Health Sciences, Health Experiences Institute, University of Oxford, Oxford, UK while the other found no such preference but provided results consistent with population health maximisation. Other studies mostly showed support for cancer but did not require a direct health trade-off. Severity and end-of-life searches identified 12 and 6 papers, respectively, which were additional to existing reviews. There is consistent evidence that people give priority to severe illness, while results for end-of-life are mixed.

Conclusion We did not find consistent support for a preference for health gains to cancer patients in the context of health maximisation. The evidence base is small and the results are highly sensitive to study design. There remains a contradiction between these findings and the popular view of cancer, and further work is required to determine the features of cancer which contribute to that view.

\section{Key Points for Decision Makers}

Policies such as the Cancer Drugs Fund in England assume there is a societal preference to fund cancer care relative to other conditions.

This review finds that although the public consistently sees cancer as 'special', in the small number of studies that present respondents directly with a health trade-off, the results do not consistently support a preference for health gains in cancer.

There may be specific attributes of health gain within the 'cancer' label that are highly valued by the public and should be considered in decision making, in a way that is not disease-specific. 


\section{Introduction}

Cancer has been described as "the emperor of all maladies" [1], and despite significant improvements in survival rates for many cancers [2], it is still a 'dreaded' disease [3]. There are instances of health policies assuming that there is a preference for society to fund cancer care, relative to other diseases and conditions. For example, in the documents establishing the original Cancer Drugs Fund (CDF) in England, there is an assumption that the public value health gains to cancer patients up to twice as much as other conditions [4]. The $\mathrm{CDF}$ is unique in providing ringfenced funds for a named disease, although there are examples of funds to cover specific types of conditions, such as the New Medicines Fund in Scotland, which supports access to drugs for end-of-life or rare conditions $[5,6]$. The end-of-life criteria used by the National Institute for Health and Care Excellence (NICE) also reflect an assumed preference for health gain to patients with limited life expectancy [7], a feature of many cancers.

Health economic analysis typically assumes that the primary role of publicly funded healthcare is to maximise population health [8]. This is operationalised in cost-effectiveness analysis by assuming that 'a quality-adjusted life-year (QALY) is a QALY', i.e. a given level of health gain is equivalent regardless of the person it accrues to; it does not generally consider aspects outside the specific definition of health used for assessment, such as characteristics of the patient, the intervention or the condition itself $[9,10]$. However, there are some particular circumstances that can be given generous weighting in NICE's Technology Appraisal Committee deliberations, including severity of disease, end of life, and illnesses in children, and these aim to reflect societal preferences for allocation of healthcare resources [11].

Giving a preference weighting to cancer, or indeed any specific feature of ill health, requires understanding the trade-off involved: does society value health gains to cancer patients more highly than gains to other patients? More specifically, are we prepared to divert resources to cancer treatment even if it results in lower health gains for the population as a whole? Prioritising one disease type in this way within a fixed budget means that health is foregone by other patients within the population; hence, it has been argued that a strong case must be made to depart from the principle of health maximisation, and that this should reflect society's views [12]. Therefore, our study aimed to explore the empirical evidence for a preference among the UK general public for health gain to cancer patients. Preliminary work indicated that limited empirical data exist specifically for cancer in the UK. To make our review more informative, we therefore chose to also look at similar data from other countries, and to consider proxies for cancer, in order to place the UK findings in context and enrich our interpretation; our focus, however, remains on the UK and cancer.

\section{Methods}

A literature review was undertaken to identify empirical studies examining societal preferences for health gain to cancer patients. A search of the MEDLINE and PubMed electronic databases was conducted during November 2015, and updated in March 2017, using search terms covering both social preferences and cancer. In addition, a search of MEDLINE was conducted for the specific types of studies that would be used to address such preferences, such as discrete-choice experiments (DCEs). EconLit searches were added in March 2017. The search strategies are reported in Online Resource 1, section A. The terms referring to societal views were restricted to the title field to select papers with a direct focus on this topic.

Papers were screened by review of the abstracts, and eligible papers identified by full-text review (by LM). Studies were included if they were empirical studies of preferences for treating cancer patients relative to other conditions, studies of public views (i.e. excluding studies of clinicians and decision makers), and written in English; unpublished papers were not included.Study authors for the UK papers directly addressing health trade-off were contacted for points of clarification. The main data extracted from the studies (by LM, reviewed by SW) were the measure of preference for cancer treatments, its value, and whether a preference was demonstrated, along with key study features. Potential sources of bias for key papers were considered and are described in the Discussion section.

We also explored the literature on preferences for notable features of cancer, specifically severity (i.e. an illness that places patients in a poor health state) and end of life (where a patient's life expectancy is short as a result of their illness). Both of these are used as prioritising features within health technology assessment, and often as proxies for cancer. While conclusions from studies in severity and end-of-life preferences do not necessarily apply to all cancers, many types of cancer will fall into at least one of these categories, therefore such studies could help support our understanding of cancer preferences. This area has been reviewed by Dolan et al. [13], Shah [14] and most recently by $\mathrm{Gu}$ et al. with searches run in August 2014 [15]. These were supplemented with MEDLINE and PubMed searches in February 2016 for additional publications since that work, with an update and Econlit searches conducted 
in March 2017 (details in Online Resource 1). Inclusion criteria were as above, replacing cancer with severity or end of life.

This report is consistent with the Preferred Reporting Items for Systematic Reviews and Meta-Analyses (PRISMA) reporting guidelines.

\section{Results}

\subsection{Identified Studies}

The literature search identified 24 empirical studies of public preferences for treating cancer (Fig. 1). Among the records recovered by the experimental method searches, the majority use contingent valuation (i.e. willingness to pay [WTP]); the initial high number of 'social value of a QALY' records were largely cost-effectiveness analyses rather than attempts to value health gain itself.

An overview of the papers is presented in Table 1 (further details are provided in Online Resource 1, sections B-D, with information on the 40 articles assessed in full). All except two papers are stated preference experiments where respondents are asked to respond to a hypothetical situation; Rojas [16] used experienced utility by asking respondents about their life satisfaction, while Gayer et al. [17] used a revealed preference approach to estimate the value of cancer risk reduction as reflected in house prices. Just over half of the studies (14/24) take a personal perspective; ten take a socially inclusive perspective, i.e. asking for preferences for a population of which they could be a member.

\section{(a) Cancer preference}

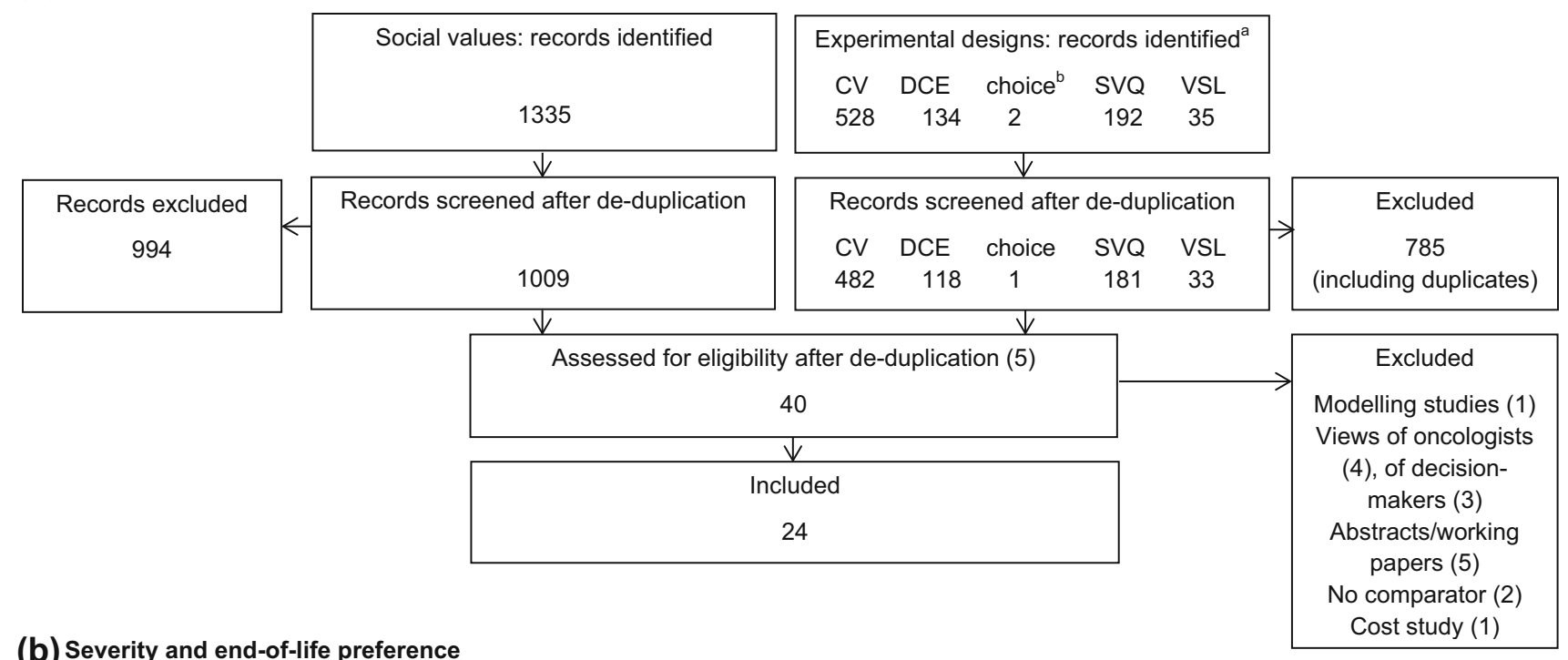

\section{(b) Severity and end-of-life preference}

Severity (published 2014-2017)

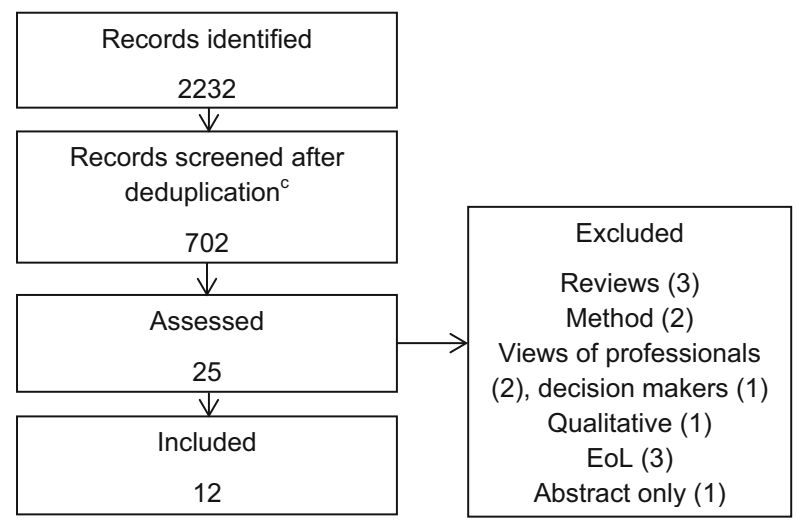

Fig. 1 Literature search results. $C V$ contingent valuation, $D C E$ discrete-choice experiment, $S V Q$ social value of a quality-adjusted life-year QALY, VSL value of a statistical life. ${ }^{\text {a}}$ Experimental design searches were run separately and then combined after deduplication
End of life (published 2014-2017)

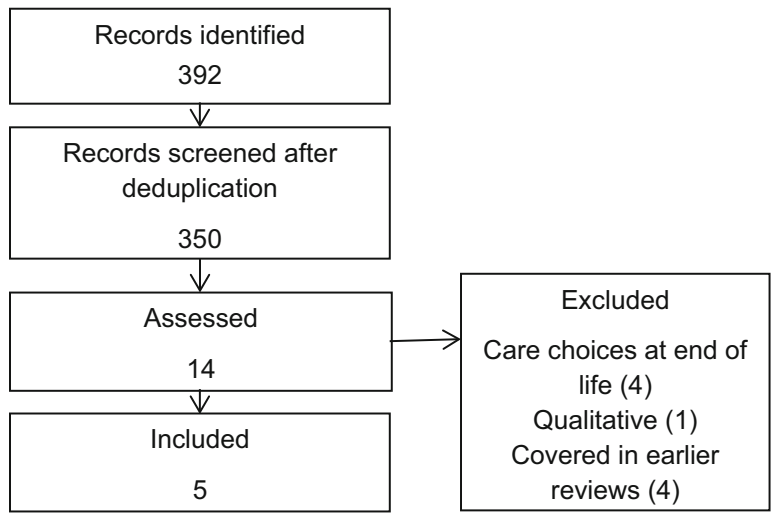

and screening. ${ }^{\mathrm{b}}$ Choice-based experiments were included as a search term to pick up choice-based designs other than the typical methods

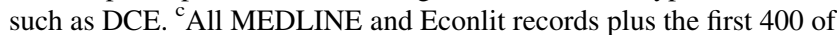
1868 from PubMed sorted by relevance 


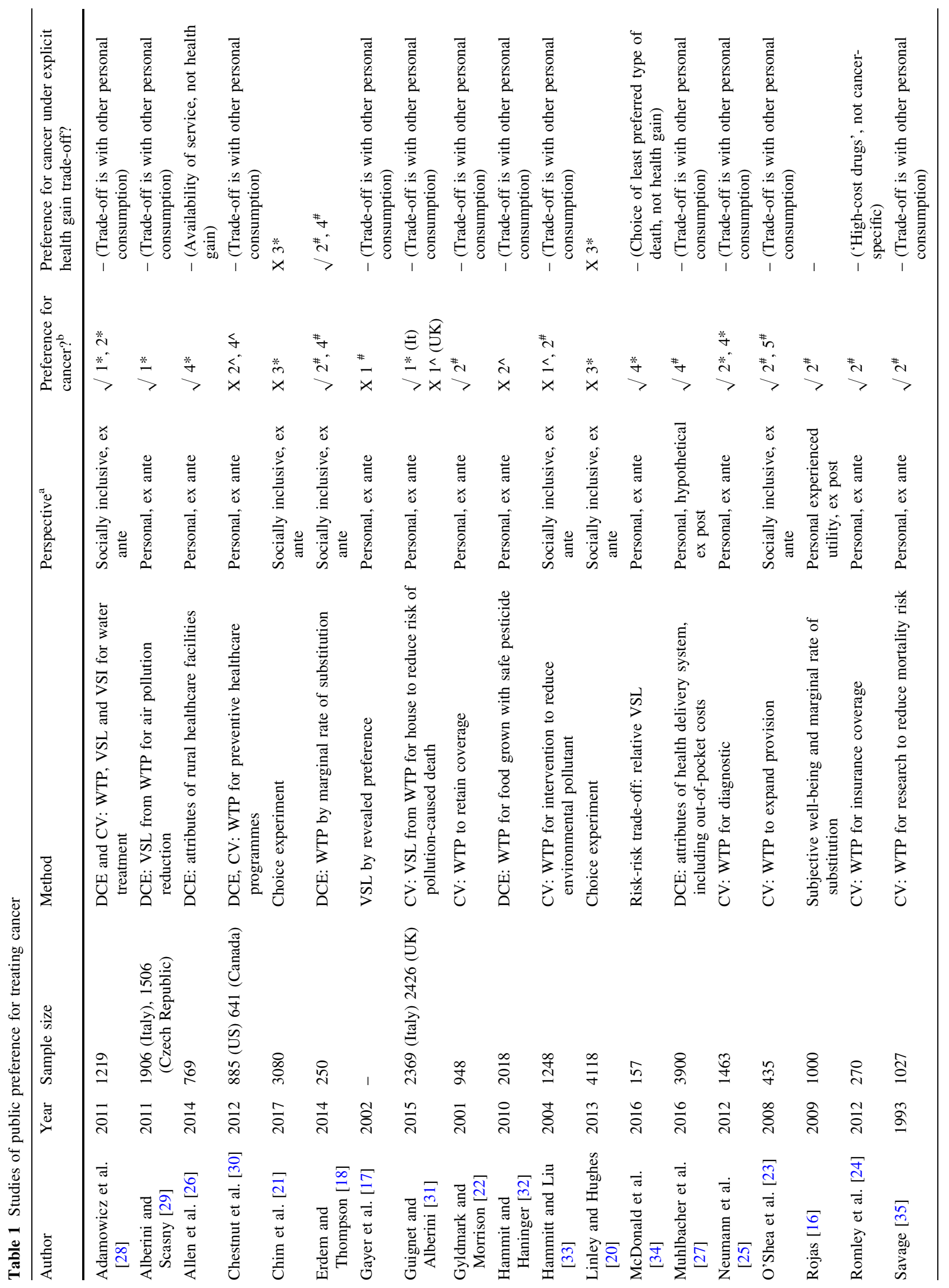




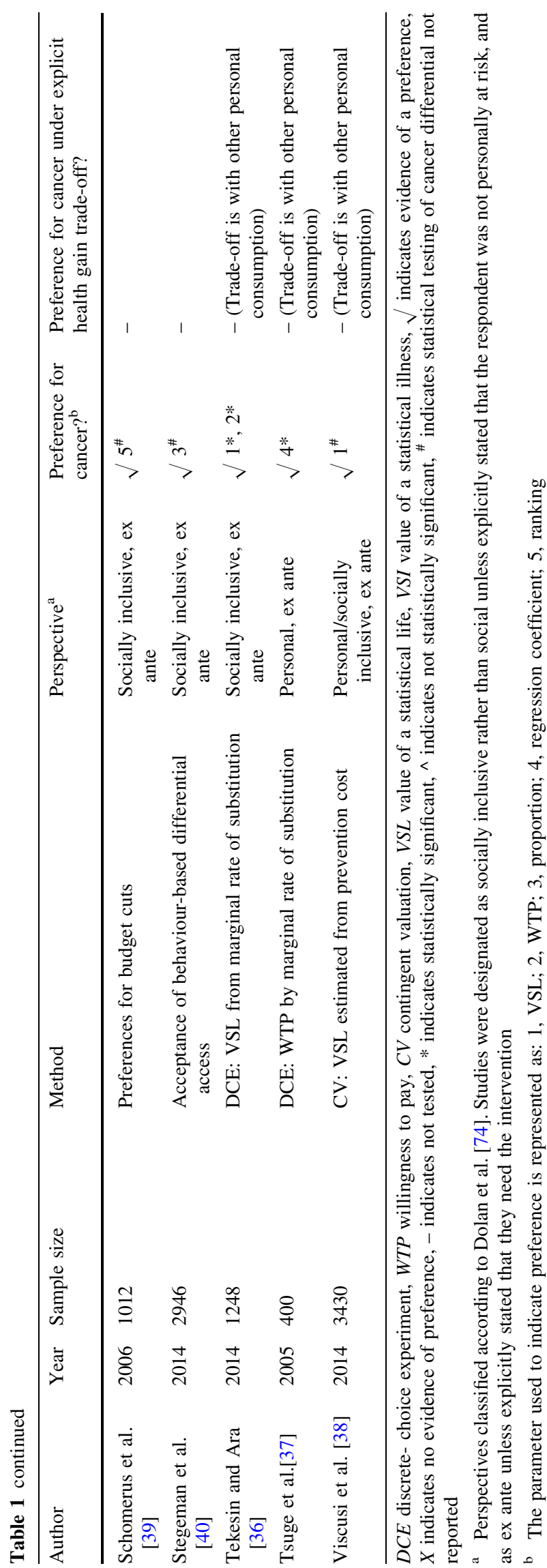

Initial analysis identified three papers that directly addressed trade-offs between health gains to cancer patients and other use of resources; two of these studies were in the UK, and are described below. Studies outside the UK, or where respondents did not face this trade-off or considered aspects other than treatment, are discussed briefly.

\subsection{Trade-Off Studies}

Erdem and Thompson [18] used a DCE to measure public preferences for attributes of healthcare innovations. In a DCE, respondents are asked to choose between two or more hypothetical scenarios, described in terms of defined attributes, which are set at various levels; choices are analysed to determine the extent to which each attribute contributes to the likelihood of a scenario being preferred. In that study, respondents were asked to choose which of two innovations their local National Health Service (NHS) should fund, described in terms of six attributes, one of which was the target population (levels: disability, cancer, mental health, obesity, asthma and drug addiction).

The study showed a significant preference for interventions for cancer patients (being a cancer intervention increased its likelihood of being chosen), and this was consistent across three clusters identified in a latent class analysis (a statistical technique to identify groups of respondents showing similar response patterns). By including cost as one of the parameters, the authors estimated WTP for the preferred characteristic, and, in the case of cancer, this was approximately $£ 40$ per month in extra taxation. This was consistently the highest among the conditions tested, across all latent groups, although the absolute value of this estimate should be treated with caution because it can be sensitive to the framing of the question; for example, framing as a monthly cost may overestimate WTP compared to a one-off fee [18], and WTP can differ for introduction of a service compared to its retention [19].

The authors showed example scenarios where an intervention for cancer patients was not the most likely to be chosen, i.e. cancer was not preferred in the absolute but could be traded off against combinations of the other parameters, such as health gain and strength of evidence.

Linley and Hughes [20] tested a range of parameters that could be used for prioritisation, in a resource allocation exercise where participants acted as a social decision maker, and allocated treatment between two groups that differed on one parameter at a time. The parameters included cancer and others, such as severity, end of life and reliance on carers. Respondents were asked to divide resources between two groups of patients, under three scenarios: all else being equal; health gain trade-off (i.e. 
the patients with the test characteristic would improve in health a little, whereas the other group would improve considerably); and cost trade-off (test characteristic group costs twice as much to treat).

With all else being equal, the data showed no preference for the cancer patients, with the majority of respondents dividing resources equally. Some of the parameters showed a significant preference (e.g. severity, reliance on carers), therefore, in principle, the study design was able to pick up such preferences. Under health gain trade-off, there was a shift in preference towards the group with the greater health gain, i.e. consistent with maximising population health rather than a preference for health gain in cancer.

Outside the UK, Chim et al. [21] fielded a study in Australia very similar to that of Linley and Hughes [20], with comparable findings, notably no evidence for a preference for health gains in cancer.

\subsection{Other Studies}

Of the remaining 21 papers, six explored respondents' WTP for specified interventions, services or coverage. Gyldmark and Morrison (Denmark) [22] aimed to test the validity of a contingent valuation design for obtaining public values, and as a measure of demand. The study evaluated WTP in insurance premium to maintain coverage for four conditions (uterine cancer, mild hypertension, diabetes in the elderly, and a broken wrist); uterine cancer showed the highest WTP of the four conditions tested. O'Shea et al. (Ireland) [23] explored WTP via tax or voluntary contribution, for cancer pain relief, community services for the elderly, or mental health. Both cancer and the elderly projects showed higher WTP than mental health. Importantly, neither of these studies controlled for severity, therefore the valuations reflect respondents' perception of the severity of the conditions and the likely health gain. Romley et al. (US) [24] estimated WTP in additional insurance premium for generous coverage of 'specialty' (i.e. high-cost) drugs. They identified a high premium, although this was not cancer-specific. Neumann et al. (US) [25] used a DCE to measure WTP for a diagnostic test, with no immediate treatment decision. Respondents were most likely to choose to test for cancer, and these tests showed the highest WTP; however, this valuation is for the test, not for any corresponding treatment. Allen et al. (US) [26] and Muhlbacher et al. (US) [27] studied the design of health delivery systems, with Muhlbacher et al. finding that out-of-pocket cost considerations were lower for lung cancer than diabetes or current health. The study by Allen et al. is more difficult to interpret, finding no significant impact on WTP for local services when adding cancer care, but a negative impact when adding diabetes care or physical therapy.
Twelve of the studies [17,28-38] estimated the value of a statistical life (VSL) for cancers by measuring WTP for reductions in cancer risk in comparison with other conditions. Scenarios typically included reduction or avoidance of environmental pollution [17, 28, 29, 31-33, 38] and comparisons with road traffic accidents [29, 34-37]. These studies are part of a body of risk literature estimating the VSL premium for cancer, reviewed by Tekesin and Ara [36], which finds cancer premiums ranging from 0 to $200 \%$. Our review identified similar mixed results, with seven of the studies showing an effect of cancer context [28, 29, 34-38], three showing no effect [17, 32, 33], and two showing mixed effects across health conditions or countries [30, 31].

While a VSL premium supports the idea of cancer 'dread', the values in these studies reflect the value of prevention rather than health gain to patients. The exception is the study by McDonald et al. (UK) [34], which uses risk-risk trade-off to separate the effects of the 'cancer' label, duration of morbidity, and delay between exposure and symptom onset (latency). Although they found some evidence that the cancer context increased VSL relative to road accidents, the effect was counterbalanced by morbidity and latency effects, such that a scenario of a generic cancer with a latency of 10 years or more, and a morbidity period of 12 months, showed no premium.

From a list of nine conditions, Schomerus et al. (Germany) [39] asked respondents to choose where cuts could be made; cancer was rarely chosen. While this finding is consistent with a view of cancer as 'special', the study did not ask respondents to make trade-offs between specified characteristics of the conditions.

Stegeman et al. (The Netherlands) [40] explored views on differential access to healthcare based on the disease, and the patient's health behaviour. Although the findings show a readiness to protect cancer patients from access sanctions, the yes/no response used in the study did not involve making a trade-off.

Rojas (Costa Rica) [16] used subjective well-being scores in a regression analysis including five conditions and income to estimate the monetary value of the illnesses; cancer had the highest monetary value at US $\$ 2700$ per month, with arthritis second at US\$1000 per month. This valuation is interpreted as the financial compensation that would return the respondent to their state of well-being before disease onset, and is not equivalent to WTP for treatment.

\subsection{Cancer Related Characteristics: Severity}

There is a body of evidence indicating that people will depart from health maximisation to prioritise severe illness, beginning with work by Nord (Norway) [41] and Ubel 
(US) [42] in the 1990s, followed by Green in the UK [43]. The majority of 19 studies reviewed by Gu et al. [15] found the public generally give priority to patients with severe disease, although the definitions of severity in the studies are different and the values found are highly sensitive to experimental design, with some suggestion of a threshold effect.

Our supplementary searches identified 12 further studies related to severity (Table 2, column 6). Two included data for the UK, and results are consistent with the findings above. Specifically, van Exel et al. [44] used a factor analysis method (Q-sort) in a European study and identified five prioritising factors, one of which related to severity combined with maximising health gains. Rowen et al. [45] found some support for severity (defined by the impact on health-related quality of life and life expectancy) as a possible weighting factor in health technology assessment, using a DCE in the UK. Of the 10 further studies (Canada [46-48], The Netherlands [49, 50], Australia [21, 51], Belgium [52], Japan [53] and Poland [54]), nine showed some level of support for prioritising by severity. Five of the 12 studies described heterogeneity of preferences, and five suggested preference for equal dispersion of gains.

\subsection{Cancer-Related Characteristics: End of Life}

There is a smaller evidence base exploring preferences for health gain for patients whose life expectancy is short as a result of disease, reviewed by Chamberlain [55] and $\mathrm{Gu}$ et al. [15], who, between them, covered 11 studies. They found mixed results, with six studies showing weak or no effect of end of life on preferences, four showing some effect, and one describing heterogeneity of views. Again, results are highly sensitive to study design. Six of those studies are from the UK, of which two showed support for preference for end-of-life treatments. Shah [56] also recently reviewed end-of-life preference and came to similar conclusions; the review provides details of selected studies and commentary on methodological challenges and future research.

Our end-of-life searches identified five additional studies, plus an additional study from the severity search, which also had end-of-life information (Table 2, column 7). Two studies used Q-sort; van Excel et al. [44] found a viewpoint relating to preservation of life in a study including the UK, but Wouters et al. [57] found no viewpoint supporting an end-of-life preference in The Netherlands. Three DCE papers from Canada [46-48], and a choice study from Australia [21], also found no preference for treating patients with a short life expectancy.

\section{Discussion}

Respondents in these studies view cancer as 'special' and deserving prioritisation, and, in some contexts, showed increased WTP (tax or personally) for cancer care or prevention. However, when presented with the opportunity cost of that choice, the results are inconsistent. As such, the literature reviewed does not provide a strong body of evidence supporting preference for health gains in cancer per $s e$, and gives no clear indication for a weighting factor. This finding is consistent with other authors' reviews (e.g. Linley and Hughes [20], Chamberlain [55] and Shah [58]); this paper updates and systematically extends that work. Evaporation of a preference for treating cancer when faced with its opportunity cost was also demonstrated by Gold et al. in a qualitative study [59]. The impact assessment for the establishment of the CDF in 2010 also found little support for its assumption of a cancer preference, and the absence of a specific cancer preference in the Linley and Hughes paper is commonly cited in critiques of the CDF, including the Scottish and Welsh governments' decisions not to implement similar funds $[60,61]$.

The evidence on severity suggests that the public show a preference for health gains to patients with severe disease; however, the support for a preference for health gains at the end of life is equivocal. The variability in these results illustrates the challenges of designing experiments to determine definitive weights for these parameters for use in Health Technology Assessments (HTAs), with the results being sensitive to framing effects (preferences shifting with different descriptions of the problem). Interpretation is further complicated by evidence of heterogeneity in attitudes within the population surveyed, raising questions of how to represent an overall societal view [56]. Examples of the use of severity in HTA include Sweden and The Netherlands (variable threshold), as well as France (as a dimension of clinical benefit assessment) [62]. End-of-life criteria are used in HTA by NICE and the Scottish Medicines Consortium, allowing more flexibility in the cost per QALY under specific criteria $[5,7]$.

As the two UK studies requiring a trade-off disagree on the role of cancer in public preferences, it is important to explore potential sources of bias. The studies differ on several design elements, which might contribute to the contradictory results, and we suggest there is an overall tendency for the study by Erdem and Thompson [18] to overestimate, and the study by Linley and Hughes [20] to underestimate, preference for cancer. First, complexity; these are difficult choices and it is possible that in the multiattribute DCE, respondents resort to simple decision heuristics [63], such as prioritising the cancer patient, to make the decision more manageable. Indeed the authors' 


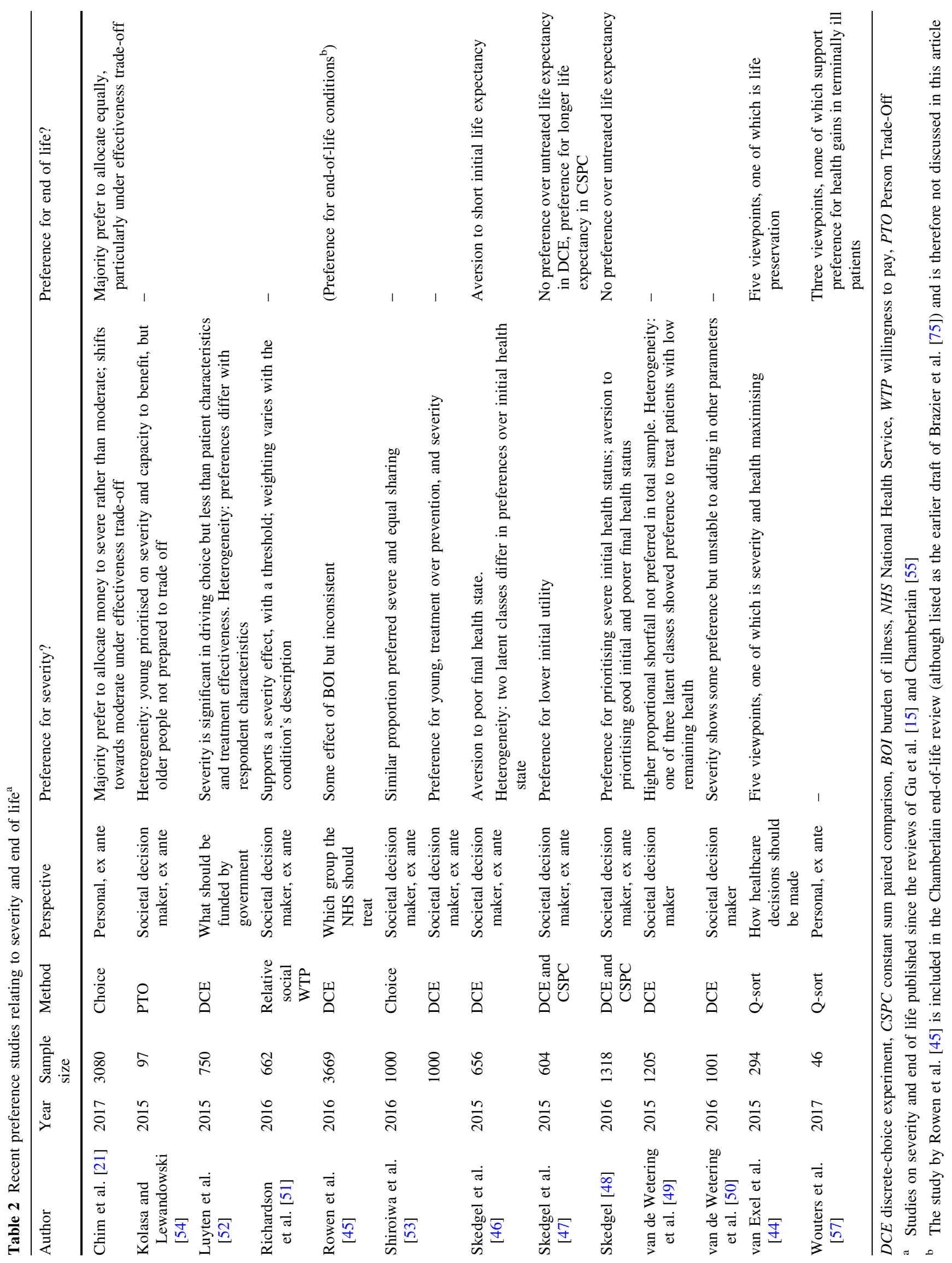


own further analysis indicated use of selection by aspects [64] and attribute non-attendance [65] in the responses, with cancer consistently attracting respondents' attention. This suggests that respondents were not fully considering the trade-offs in the scenarios, which resulted in overestimation of coefficients and WTP for cancer. The Linley and Hughes study [20] describes the choice in a simple health gain scenario. It may be that this provides respondents with a stark picture of the implications of favouring a particular group, in which the opportunity cost implications are not acceptable to the majority of respondents.

Second, the choices permitted: the DCE requires an allor-nothing choice between two options (and a 'none' option), whereas the single parameter choice experiment in effect offers an 11-point scale. A forced choice can overestimate the degree of preference, particularly if there is a uniform direction of preference among respondents, but only a minimal perceived difference between the options. The results reflect the number of respondents with a given preference, but not the extent of that preference. In contrast, the scale may underestimate preference because of central tendency bias (respondents under-using the extremes of a scale). A similar hypothesis was tested by Skedgel et al., who compared the results of a binary-choice DCE with constant-sum paired comparison (budget sharing) and found that allowing respondents to distribute a budget across two alternatives provided richer preference data [47].

Third, the DCE may be sensitive to the choice of comparator conditions, which include conditions that might be considered behaviour-related (such as obesity), and where cancer is the only one that is typically considered immediately life-threatening. Any bias is likely to be in favour of cancer in this context.

Finally, both studies are limited in some aspect of generalisability. Erdem and Thomson report a relatively small and localised study (250 respondents in West Yorkshire), which may not be broadly generalizable for the UK, although comparison with the 2011 census indicated the sample was similar to the West Yorkshire population. The Linley and Hughes study provides a simple choice scenario; however, in reality, healthcare prioritisation is complex and based on multiple criteria, as outlined by Erdem and Thompson, therefore the single-parameter approach may not generalise to complex decisions. The direction of potential bias here is non-obvious.

Despite the inconsistency of results in this specific resource allocation context, there is a strong response to cancer in many of the studies reviewed. This is consistent with dual-processing theories of cognition as outlined by Kahneman [66], who described one processing system as fast and intuitive (System 1), while the other is slower and more deliberate (System 2). Using this model, we can describe the immediate responses to questions on cancer as triggering System 1, responding based on fear and dread, with trade-off questions that require further consideration invoking System 2. Simple heuristics in complex scenarios may be dominated by System 1, and not checked by System 2 so long as the resultant choices are coherent and acceptable. A similar explanation was proposed by Robb et al. [3] for qualitative observations of respondents responding initially to cancer questions with dread, while also acknowledging significant improvements in outcomes. Shah et al. [67] also observed participants in qualitative research struggling to reconcile logical resource allocation decisions with their intuitive response. Although there have been recent critiques of Kahneman's work [68], it provides a useful structure for exploring the implications of the study's findings. For example, it may be that the application of accountability for reasonableness principles [69] by HTA agencies (e.g. NICE [70]) makes these processes inherently reliant on System 2 judgements, and this will contribute to decisions being seen as unacceptable by the public if they are responding based on System 1.There are also implications for preference research, including the need for researchers to be clear on which type of response they are aiming to measure, and careful consideration of language in the materials and questions presented to respondents, with prior qualitative work to identify 'trigger' words that could prompt use of a simple heuristic. Parallel qualitative work with survey respondents may also help to understand the basis for their choices, as described by Shah [56].

\subsection{Limitations and Further Research}

At the review level, we suggest that the main risk of bias across studies is likely to be publication bias. It may be that negative results (i.e. showing no evidence of a cancer preference) have a lower probability of publication, hence this review would overestimate any preferences.

The review is limited by the small number of studies that address the question of the value of health gains in cancer directly. This probably stems from the focus in economic evaluation on generic measures of health to allow comparison across disease areas; standard textbooks recommend that studies valuing health states are not labelled with specific conditions, and the value tariffs in common use were generated using unlabelled health state descriptions [71]. The impact of named conditions on how the public values health states has been reviewed by Brazier et al. [71] and Rowen et al. [72], showing mixed results. The study by Rowen et al. finds a reduction in the values assigned to severe health states labelled as cancer compared with irritable bowel syndrome (IBS) or no label [72]. In a study not covered in these reviews, Mason et al. 
[73] used named conditions in a prioritising exercise and did not observe cancer behaving noticeably differently from the other conditions; however, they do comment that familiar conditions such as cancer tended to receive more extreme scores, with less familiar illnesses more likely to be ranked in the middle. Despite the inconsistencies between studies, it appears that the name of the condition can be important in how the public value a given state, which, by extension, could affect the value of any health gain. Focusing on disease-blind health state valuations may be obscuring such public preferences.

Our review is limited by its focus specifically on societal attitudes to cancer in the context of resource allocation and health maximisation; however, we cannot ignore the reaction to cancer seen in other types of studies. Our conclusions are rooted in a health maximisation paradigm, which does not explicitly consider broader aspects beyond health gain. An alternative view that maximised something other than health (for example, utility as in welfare economics) would use measures such as individual WTP, which can be considered as a holistic reflection of what is important to the individual. In our review, such studies showed a cancer preference, suggesting there are features associated with cancer that are not reflected in standard measures of health. This potentially leads to undervaluation of interventions in health technology assessment, not only in cancer but also in other diseases, if aspects that are valued by the public are not captured. We hypothesise that the apparent uniqueness of cancer may be in the particular combination of such features, including, for example, the impact on the family, or the value of hope. Further research is needed to explore characteristic features of cancer in comparison with other significant health conditions such as cardiovascular disease and dementia. Our future work aims to identify broader aspects of health outcome that contribute to the value that patients and the public attach to therapeutic interventions.

\section{Conclusions}

This review did not find consistent support for a preference for health gains to cancer patients in the specific context of resource allocation. However, the evidence base is small due to the focus in health economics on condition-blind valuation, and the results are highly sensitive to study design. There remains a contradiction between the findings and the popular view of cancer. Further understanding of the features that contribute to that view may reveal additional aspects of outcome that are valued by the public and could be considered when technologies are evaluated for funding.
Acknowledgements The authors thank the three anonymous reviewers for their contributions.

Author contributions Liz Morrell designed and executed the search strategy, carried out the review, and wrote the manuscript. Sarah Wordsworth provided overall guidance, reviewed the extracted data, and commented on the manuscript. Sian Rees and Richard Barker commented on the manuscript. All authors reviewed the final manuscript. Liz Morrell acts as overall guarantor.

\section{Compliance with Ethical Standards}

Funding This work was funded by a grant from the Policy Department, Cancer Research UK, to the Centre for the Advancement of Sustainable Medical Innovation (CASMI: LM, RB). The funder had no role in the conduct of the study or writing of the manuscript, but has reviewed a draft of the manuscript. Open access publishing of this article is funded by the UK Charities Open Access Fund allocation to the University of Oxford.

Conflict of interest Liz Morrell and Sarah Wordsworth declare that they have no conflicts of interest to declare. Sian Rees has received fees from Takeda for leadership training, and Richard Barker is a nonexecutive director of Celgene Corporation.

Ethical approval This article does not contain any studies with human participants or animals performed by any of the authors.

Informed consent Not applicable.

Availability of data and material The full search results are available from the corresponding author on reasonable request.

Open Access This article is distributed under the terms of the Creative Commons Attribution 4.0 International License (http://creativecommons.org/licenses/by/4.0/), which permits unrestricted use, distribution, and reproduction in any medium, provided you give appropriate credit to the original author(s) and the source, provide a link to the Creative Commons license, and indicate if changes were made.

\section{References}

1. Mukherjee S. The emperor of all maladies. Harper Collins: Fourth Estate; 2011

2. Walters S, Benitez-Majano S, Muller P, Coleman MP, Allemani $\mathrm{C}$, Butler $\mathrm{J}$, et al. Is England closing the international gap in cancer survival? Br J Cancer. 2015;113(5):848-60. doi:10.1038/ bjc.2015.265.

3. Robb K, Simon A, Miles A, Wardle J. Public perceptions of cancer: a qualitative study of the balance of positive and negative beliefs. BMJ Open. 2014;4:e05434. doi:10.1136/bmjopen-2014005434.

4. Department of Health. Impact assessment of a proposal for a Cancer Drugs Fund. 2010. http://www.dh.gov.uk/prod_consum dh/groups/dh_digitalassets/@dh/@en/documents/digitalasset/dh_ 120930.pdf. Accessed 1 Oct 2015.

5. Scottish Medicines Consortium. PACE (Patient \& Clinician Engagement) overview document. 2014. http://www.scottish medicines.org.uk/files/PACE/PACE_Overview_Document_FINAL .pdf. Accessed 19 Nov 2016. 
6. The Scottish Government. Fund for new medicines doubles. $2015 . \quad \mathrm{http}: / /$ news.scotland.gov.uk/News/Fund-for-newmedicines-doubles-18eb.aspx. Accessed 18 May 2015.

7. NICE. Guide to the methods of technology appraisal. 2013. http:// www.nice.org.uk/article/pmg9/resources/non-guidance-guide-tothe-methods-of-technology-appraisal-2013-pdf. Accessed 16 Jan 2017.

8. Culyer AJ. The dictionary of health economics. 2nd ed. Cheltenham: Edward Elgar; 2010.

9. Coast J, Smith RD, Lorgelly P. Welfarism, extra-welfarism and capability: the spread of ideas in health economics. Soc Sci Med. 2008;67(7):1190-8.

10. Coast J. Maximisation in extra-welfarism: a critique of the current position in health economics. Soc Sci Med. 2009;69(5):786-92. doi:10.1016/j.socscimed.2009.06.026.

11. Rawlins M, Barnett D, Stevens A. Pharmacoeconomics: NICE's approach to decision-making. $\mathrm{Br} \mathrm{J}$ Clin Pharmacol. 2010;70(3):346-9. doi:10.1111/j.1365-2125.2009.03589.x.

12. Culyer AJ. Ethics, priorities and cancer. J Cancer Policy. 2017;11:6-11. doi:10.1016/j.jcpo.2016.09.007.

13. Dolan P, Shaw R, Tsuchiya A, Williams A. QALY maximisation and people's preferences: a methodological review of the literature. Health Econ. 2005;14:197-208. doi:10.1002/hec.924.

14. Shah K. Severity of illness and priority setting in healthcare: a review of the literature. Health Policy. 2009;93:77-84. doi:10. 1016/j.healthpol.2009.08.005.

15. Gu Y, Lancsar E, Ghijben P, Butler JRG, Donaldson C. Attributes and weights in health care priority setting: a systematic review of what counts and to what extent. Soc Sci Med. 2015;146:41-52. doi:10.1016/j.socscimed.2015.10.005.

16. Rojas M. Monetary valuation of illnesses in Costa Rica: a subjective well-being approach. Rev Panam Salud Publica. 2009;26(3):255-65.

17. Gayer T, Hamilton JT, Viscusi WK. The market value of reducing cancer risk: hedonic housing prices with changing information. South Econ J. 2002;69(2):266-89.

18. Erdem S, Thompson C. Prioritising health service innovation investments using public preferences: a discrete choice experiment. BMC Health Serv Res. 2014;14:360 10.1186/1472-696314-360.

19. O’Brien B, Gafni A. When do the "dollars" make sense? Toward a conceptual framework for contingent valuation studies in health care. Med Decis Mak. 1996;16(3):288-99.

20. Linley WG, Hughes DA. Societal views on NICE, cancer drugs fund and value-based pricing criteria for prioritising medicines: a cross-sectional survey of 4118 adults in Great Britain. Health Econ. 2013;22(8):948-64.

21. Chim L, Salkeld G, Kelly P, Lipworth W, Hughes DA, Stockler MR. Societal perspective on access to publicly subsidised medicines: a cross sectional survey of 3080 adults in Australia. PloS One. 2017;12(3):e0172971.

22. Gyldmark M, Morrison GC. Demand for health care in Denmark: results of a national sample survey using contingent valuation. Soc Sci Med. 2001;53(8):1023-36.

23. O'Shea E, Gannon B, Kennelly B. Eliciting preferences for resource allocation in mental health care in Ireland. Health Policy. 2008;88(2-3):359-70.

24. Romley JA, Sanchez Y, Penrod JR, Goldman DP. Survey results show that adults are willing to pay higher insurance premiums for generous coverage of specialty drugs. Health Affairs. 2012;31(4):683-90.

25. Neumann PJ, Cohen JT, Hammitt JK, Concannon TW, Auerbach HR, Fang C, et al. Willingness-to-pay for predictive tests with no immediate treatment implications: a survey of US residents. Health Econ. 2012;21(3):238-51.
26. Allen JE, Davis AF, Hu W, Owusu-Amankwah E. Residents' willingness-to-pay for attributes of rural health care facilities. J Rural Health. 2015;31(1):7-18.

27. Muhlbacher AC, Bethge S, Reed SD, Schulman KA. Patient preferences for features of health care delivery systems: a discrete choice experiment. Health Serv Res. 2016;51(2):704-27.

28. Adamowicz W, Dupont D, Krupnick A, Zhang J. Valuation of cancer and microbial disease risk reductions in municipal drinking water: an analysis of risk context using multiple valuation methods. J Environ Econ Manag. 2011;61(2):213-26. doi:10.1016/j.jeem.2010.10.003.

29. Alberini A, Scasny M. Context and the VSL: evidence from a stated preference study in Italy and the Czech Republic. Environ Resour Econ. 2011;49(4):511-38. doi:10.1007/s10640-010-9444-8.

30. Chestnut LG, Rowe RD, Breffle WS. Economic valuation of mortality-risk reduction: stated preference estimates from the United States and Canada. Contemp Econ Policy. 2012;30(3):399-416.

31. Guignet D, Alberini A. Can property values capture changes in environmental health risks? Evidence from a stated preference study in Italy and the United Kingdom. Risk Anal. 2015;35(3):501-17.

32. Hammitt JK, Haninger K. Valuing fatal risks to children and adults: effects of disease, latency, and risk aversion. J Risk Uncertain. 2010;40(1):57-83. doi:10.1007/s11166-009-9086-9.

33. Hammitt JK, Liu J-T. Effects of disease type and latency on the value of mortality risk. J Risk Uncertain. 2004;28(1):73-95. doi:10.1023/B:RISK.0000009437.24783.e1.

34. McDonald RL, Chilton SM, Jones-Lee MW, Metcalf HRT. Dread and latency impacts on a VSL for cancer risk reductions. J Risk Uncertain. 2016;52(2):137-61. doi:10.1007/s11166-016-9235-x.

35. Savage I. An empirical investigation into the effect of psychological perceptions on the willingness-to-pay to reduce risk. J Risk Uncertain. 1993;6(1):75-90.

36. Tekesin C, Ara S. Measuring the value of mortality risk reductions in Turkey. Int $\mathrm{J}$ Environ Res Public Health. 2014;11(7):6890-922.

37. Tsuge T, Kishimoto A, Takeuchi K. A choice experiment approach to the valuation of mortality. J Risk Uncertain. 2005;31(1):73-95. doi:10.1007/s11166-005-2931-6.

38. Viscusi WK, Huber J, Bell J. Assessing whether there is a cancer premium for the value of a statistical life. Health Econ. 2014;23(4):384-96.

39. Schomerus G, Matschinger H, Angermeyer MC. Preferences of the public regarding cutbacks in expenditure for patient care: are there indications of discrimination against those with mental disorders? Social Psychiatry Psychiatr Epidemiol. 2006;41(5):369-77.

40. Stegeman I, Willems DL, Dekker E, Bossuyt PM. Individual responsibility, solidarity and differentiation in healthcare. J Med Ethics. 2014;40(11):770-3.

41. Nord E. The trade-off between severity of illness and treatment effect in cost-value analysis of health care. Health Policy. 1993;24:227-38.

42. Ubel P. How stable are people's preferences for giving priority to severely ill patients? Social Sci Med. 1999;49:895-903.

43. Green C. Investigating public preferences on 'severity of health' as a relevant condition for setting healthcare priorities. Soc Sci Med. 2009;68:2247-55. doi:10.1016/j.socscimed.2009.03.020.

44. van Exel J, Baker R, Mason H, Donaldson C, Brouwer W. Public views on principles for health care priority setting: findings of a European cross-country study using Q methodology. Soc Sci Med. 2015;126:128-37. doi:10.1016/j.socscimed.2014.12.023.

45. Rowen D, Brazier J, Mukuria C, Keetharuth A, Risa Hole A, Tsuchiya A, et al. Eliciting societal preferences for weighting 
QALYs for burden of illness and end of life. Med Decis Mak. 2016;36(2):210-22. doi:10.1177/0272989X15619389.

46. Skedgel C, Wailoo A, Akehurst R. Societal preferences for distributive justice in the allocation of health care resources: a latent class discrete choice experiment. Med Decis Mak. 2015;35:94-105. doi:10.1177/0272989X14547915.

47. Skedgel CD, Wailoo AJ, Akehurst RL. Choosing vs. allocating: discrete choice experiments and constant-sum paired comparisons for the elicitation of societal preferences. Health Expect. 2015;18:1227-40. doi:10.1111/hex.12098.

48. Skedgel C. The prioritization preferences of pan-Canadian Oncology Drug Review members and the Canadian public: a stated-preferences comparison. Curr Oncol. 2016;23(5):322-8. doi: $10.3747 / \mathrm{co} .23 .3033$.

49. van de Wetering L, van Exel J, Bobinac A, Brouwer WB. Valuing QALYs in relation to equity considerations using a discrete choice experiment. Pharmacoeconomics. 2015;33(12):1289-300. doi:10.1007/s40273-015-0311-x.

50. van de Wetering EJ, van Exel NJ, Rose JM, Hoefman RJ, Brouwer WB. Are some QALYs more equal than others? Eur J Health Econ. 2016;17(2):117-27. doi:10.1007/s10198-014-06576.

51. Richardson J, Iezzi A, Maxwell A. How important is severity for the evaluation of health services: new evidence using the relative social willingness to pay instrument. Eur J Health Econ. 2016. doi:10.1007/s10198-016-0817-y. [Epub 25 Jul 2016].

52. Luyten J, Kessels R, Goos P, Beutels P. Public preferences for prioritizing preventive and curative health care interventions: a discrete choice experiment. Value Health. 2015;18:224-33. doi:10.1016/j.jval.2014.12.007.

53. Shiroiwa T, Saito S, Shimozuma K, Kodama S, Noto S, Fukuda T. Societal preferences for interventions with the same efficiency: assessment and application to decision making. Appl Health Econ Health Policy. 2016;14(3):375-85. doi:10.1007/s40258-0160236-3.

54. Kolasa K, Lewandowski T. Does it matter whose opinion we seek regarding the allocation of healthcare resources? A case study. BMC Health Serv Res. 2015;15:564. doi:10.1186/s12913-0151210-8.

55. Chamberlain CA. Access to non-curative anti-cancer therapies on the NHS the role of the Cancer Drugs Fund. Bristol: University of Bristol; 2015.

56. Shah K. Does society place special value on end of life treatments? In: Round J, editor. Care at the end of life: an economic perspective. Cham: Springer; 2016.

57. Wouters S, van Exel J, Baker R, Brouwer BFW. Priority to end of life treatments? Views of the public in the Netherlands. Value Health. 2017;20(1):107-17. doi:10.1016/j.jval.2016.09.544.

58. Shah KK. Is willingness to pay higher for cancer prevention and treatment? J Cancer Policy. 2017;11:60-4. doi:10.1016/j.jcpo. 2016.09.006.

59. Gold MR, Franks P, Siegelberg T, Sofaer S. Does providing costeffectiveness information change coverage priorities for citizens acting as social decision makers? Health Policy. 2007;83(1):65-72. doi:10.1016/j.healthpol.2006.11.012.

60. Williamson D. Public backs plan not to ring-fence cancer drug fund say researchers. Wales Online. 16 Aug 2012.
61. The Scottish Parliament. Meeting of Parliament. 2013. http:// www.scottish.parliament.uk/parliamentarybusiness/report. aspx?r=8142\&mode=html. Accessed 11 Feb 2016.

62. Franken M, Stolk E, Scharringhausen T, de Boer A, Koopmanschap M. A comparative study of the role of disease severity in drug reimbursement decision making in four European countries. Health Policy. 2015;119:195-202. doi:10.1016/j.healthpol. 2014.10.007.

63. Ryan M, Gerard K. Using discrete choice experiements to value health care programmes: current practice and future research reflections. Appl Health Econ Health Policy. 2003;2(1):55-64.

64. Erdem S, Campbell D, Thompson C. Elimination and selection by aspects in health choice experiments: prioritising health service innovations. J Health Econ. 2014;38:10-2. doi:10.1016/j. jhealeco.2014.06.012.

65. Erdem S, Campbell D, Hole AR. Accounting for attribute-level non-attendance in a health choice experiment: does it matter? Health Econ. 2015;24(7):773-89. doi:10.1002/hec.3059.

66. Kahneman D. Thinking, fast and slow. London: Allen Lane; 2011.

67. Shah K, Chapman A, Devlin N, Barnsley P. Do respondents completing abstract, hypothetical priority-setting exercises agree with the policy implications of their choices? Office for Health Economics. 2015. https://www.ohe.org/publications/. Accessed 2 Sep 2015.

68. Schimmack U, Heene M, Kesavan K. Reconstruction of a train wreck: how priming research went off the rails. 2017. https:// replicationindex.wordpress.com/2017/02/02/reconstruction-of-atrain-wreck-how-priming-research-went-of-the-rails/commentpage-1/. Accessed 25 Mar 17.

69. Daniels N. Accountability for reasonableness: establishing a fair process for priority setting is easier than agreeing on principles. BMJ. 2000;321(7272):1300-1.

70. NICE. Social value judgements: principles for the development of NICE guidance. 2nd edition. 2008. http://www.nice.org.uk/ Media/Default/About/what-we-do/Research-and-development/ Social-Value-Judgements-principles-for-the-development-of-NICEguidance.pdf. Accessed 2 June 2015.

71. Brazier J, Ratcliffe J, Salomon JA, Tsuchiya A. Measuring and valuing health benefits for economic evaluation. Oxford: Oxford University Press; 2009.

72. Rowen D, Brazier J, Tsuchiya A, Young T, Ibbotson R. It's all in the name, or is it? The impact of labeling on health state values. Med Decis Mak. 2012;32(1):31-40. doi:10.1177/ 0272989X11408435.

73. Mason H, Baker R, Donaldson C. Understanding public preferences for prioritizing health care interventions in England: does the type of health gain matter? J Health Serv Res Policy. 2011;16(2):81-9. doi:10.1258/jhsrp.2010.010039.

74. Dolan P, Olsen JA, Menzel P, Richardson J. An inquiry into the different perspectives that can be used when eliciting preferences in health. Health Econ. 2003;12:545-51. doi:10.1002/hec.760.

75. Brazier J, Rowen D, Murkuria C, Whyte S, Keetharuth A, Rise Hole A, Tsuchiya A, Shackley P. Eliciting societal preferences for burden of illness, therapeutic improvement and end of life for value based pricing: a report of the main survey. 2013. http:// www.eepru.org.uk. Accessed 19 Apr 2017. 